\title{
CAROTID BODY TUMOR - A CASE REPORT
}

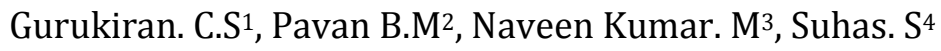

\section{HOW TO CITE THIS ARTICLE:}

Gurukiran C. S, Pavan B.M, Naveen Kumar M, Suhas S. "Carotid body tumor - A Case Report". Journal of Evolution of Medical and Dental Sciences 2013; Vol2, Issue 33, August 19; Page: 6223-6227.

\begin{abstract}
Carotid body tumors are rare neoplasms, which typically present as a slow growing, painless neck mass found along the anterior border of the sternocleidomastoid muscle. All borders were well-defined. It was non pulsatile, had no cranial nerve involvement. Neck glands were not enlarged. Her haematological and biochemical investigations did not reveal any abnormality. These tumors are generally benign but possess aggressive local growth potential. A 50 year female patient presented with a large $(70 \times 50 \times 45 \mathrm{~mm})$ sized swelling on the left side of the neck in the anterior triangle. CT with contrast revealed a hyper vascular lesion $5 \times 4 \mathrm{~cm}$ at the carotid fork and not attached to the vessel (Shamblin type II).The operation was performed under general anaesthesia with endotracheal intubation. There were a lot of feeding vessels between the tumour mass and external and common carotid artery. The tumour was excised along the subadventitial plane. Histological examination of the tumor mass was done and it revealed typical features of nonsecreting paraganglioma. The patient recovered well from the effect of anaesthesia and there were no neurological deficit. Therefore, definitive treatment requires surgical resection. Paragangliomas (PGLs) are extra-adrenally located in $10 \%$ of cases. The authors describe a case of a patient with a carotid body tumor and review the most recent literature on this unusual topic.
\end{abstract}

KEY WORDS: carotid body tumor, paraganglioma, modified shobinger.

INTRODUCTION: Carotid body tumors (CBT) are distinctly uncommon hypervascular neck tumors. $^{1-3}$ They arise from glomus bodies (paraganglia) located in the crotch of the external and internal artery, at the level of carotid bifurcation. Carotid paraganglia are composed of chemoreceptor cells derived from the carotid primitive neural crest.1, ${ }^{4}$ In general, tumors arising from any paraganglionic tissue are best called paragangliomas (PGLs) and are arbitrarily classified by their relationship to the adrenal gland (adrenal medullary tumors or pheochromocytomas and extra-adrenal PGLs). Carotid body tumour is the most common form of paraganglioma of the head and neck region ${ }^{5}$. It is usually benign and non-functional. It grows and expands slowly and rarely metastasises.5, ${ }^{5}$. A surgical classification for carotid body tumours was proposed by SHAMBLIN et al. in 1971. Group I: tumours are relatively small with minimal attachment to the carotid vessels, and surgical excision can be performed safely. Group II: tumours are larger with moderate arterial attachments and can be resected with precise surgical dissection. Group III: tumours are large neoplasms encasing the carotid arteries and can be resected only with arterial sacrifice.

CASE REPORT: A 50 year female patient presented with a large $(70 \times 50 \times 45 \mathrm{~mm})$ sized swelling on the left side of the neck in the anterior triangle. The swelling was non-tender having restricted mobility particularly in vertical axis, lying anterior to the sternocleidomastoid muscle having no fixity to the muscle or skin either. All borders were well-defined. It was non pulsatile, had no cranial nerve involvement. Neck glands were not enlarged. Her haematological and biochemical investigations did not reveal any abnormality. CT with contrast revealed a hypervascular lesion $5 \times 4$ 
$\mathrm{cm}$ at the carotid fork and not attached to the vessel (Shamblin type II). The operation was performed under general anaesthesia with endotracheal intubation. A modified shobinger incision was made in the neck and flaps elevated. The tumour was exposed after dissecting the carotids. There were a lot of feeding vessels between the tumour mass and external and common carotid artery. Internal jugular vein was dissected free and preserved. The tumour was excised along the subadventitial plane. Haemostasis was ensured and the wound was closed keeping a closed suction drainage system in situ. Histological examination of the tumor mass was done and it revealed typical features of non-secreting paraganglioma. The patient recovered well from the effect of anaesthesia and there were no neurological deficit

DISCUSSION: Paragangliomas (PGLs) are extra-adrenally located in $10 \%$ of cases. $90 \%$ of these extra-adrenal PGLs are located in the abdomen, mainly in chromaffin cells of the organ of Zuckerkandl. The remaining $10 \%$ of the extra-abdominal PGL include CBT and glomus tumours. ${ }^{6}$ The carotid body is a vascular reddish-brown structure about the size of a grain of rice located within adventitia posteromedial to bifurcation of the common carotid artery. The carotid body acts as a chemoreceptor responding to variations in oxygen tension and carbon dioxide concentrations; henceforth alternatively named chemodectomas. ${ }^{7}$ CBT usually presents in the fourth to sixth decades of life (age range: 3 months-89 years). The average tumour size is $4.5 \mathrm{~cm} \times 3.5 \mathrm{~cm} \times 3 \mathrm{~cm}$, with the largest ones exceeding $15 \mathrm{~cm}$ in diameter and weighing $200 \mathrm{~g}$. Three different types of carotid body tumors (CBTs) are described: sporadic, familial, hyperplastic. The sporadic form is the most common type, representing approximately $85 \%$ of carotid body tumors (CBTs). The familial type $(10-50 \%)$ is more common in younger patients. The hyperplastic form is very common in patients with chronic hypoxia, which includes those patients living at a high altitude ( $>5000$ feet above sea level), like those patients living in New Mexico, Peru and Colorado. The hyperplastic form is also seen in patients who have chronic obstructive pulmonary disease (COPD) or cyanotic heart disease. The incidence of bilateral CBT varies from $10 \%$ to $25 \%$ in different series. ${ }^{8}$ Here a case of sporadic CBT measuring $70 \times 50 \times 45 \mathrm{~mm}$ in size in a 50 years male patient has been described Most of the lesions are benign, but malignant lesions are seen in 6\%-12\% of cases. The diagnosis of malignancy is reserved for tumours with local, regional and distantmetastasis ${ }^{9}$. There are no histological features that distinguish benign from malignant lesions. Between 10\%and 50\% of PGLs are hereditary (autosomal dominant) due to alterations in genes coding for succinate ubiquinone oxidoreductase subunit D (SDHD), B (SDHB) and C (SDHC).10 Patients with CBT typically present with a painless mass in the angle of the jaw that may be partially covered by the sternocleidomastoid muscle. These vascular tumours may transmit pulsations from nearby carotid arteries or may be pulsatile inherently. At the time of diagnosis, cranial nerve palsies are present in $10 \%$ of cases with the X, XII, V and VII cranial nerves commonly involved in decreasing order of frequency, while the involvement of cervical sympathetic chain produces ipsilateral Horner's syndrome. Carotid sinus syndrome with bradycardia, hypotension and unconsciousness can occur spontaneously or secondary to head movement or pressure on the tumour. Episodic symptoms of pheochromocytoma are seen in 1\%-3\% of cases. The size of the tumour is important not only for the clinical manifestations, but also for a decision on treatment. In 1971, Shamblin introduced a classification system based on the tumour size, classifying small tumours which could easily be resected from the vessels as Group I. Group II includes tumours that are intimately associated and 


\section{CASE REPORT}

compressed carotid vessels, but that could be resected with careful subadventitial dissection. Group III consists of tumours that are large and typically encase the carotid artery, requiring complete or partial vessel resection and replacement. ${ }^{11}$ Here a case of CBT of Shamblin Group III has been presented.

Ultrasound studies in both sides of the neck, may exclude the presence of lymph nodes, thyroid or brachial cysts. In most cases, color-coded Doppler sonography evaluates the hypervascularity and upward intratumoural blood flow in a neck mass at carotid angle, suggesting a CBT. Accurate diagnosis is based on angiographic criteria, the most reliable of these being the separation and splaying of internal and external carotid arteries (known as the lyre sign). On CT scanning, CBT is easily recognized as hypervascular mass located at the carotid bifurcation, changing the architecture of the angle between the internal and external carotid artery, bringing them apart from each other resembling a saddle. Arterial anatomy of carotid vessels and their relationship to an enhancing lesion of the neck can also evaluated by CT angiography. MRI is the most important imaging modality in evaluating CBTs in relation to surrounding soft tissue and vascular structures. Total body scintigraphy using 123I-MIBG is used as a screening tool to detect distant additional primary or metastatic lesion in patients or their relatives.

Biochemical assays are routinely employed for the diagnosis of a functioning tumour, irrespective of symptoms. The usual methods are measurement of urinary free catecholamines and its metabolites VMA and MNs in a 24-hour urine sample. Histopathologically, CBT are firm, rubbery well-encapsulated masses composed of nests of epitheloid cells (chief cells), with clear cytoplasm separated by delicate stroma (zellballen pattern). ${ }^{7}$

The success in treating benign and malignant CBT is based on early diagnosis, complete resection of the tumour after an adequate catecholamine blockade, which is given prophylactically. Complete resection of the primary mass is the treatment of choice. Postoperative cranial nerve deficits and arterial injury have remained a significant problem. Patients with larger tumours have an increased incidence of complications. Endovascular embolisation may reduce the operative time and limit blood loss. Though we do not employ this technique preoperatively most surgeons now prefer this technique for larger tumours of Shamblin Grade III. In patients who are not suited for surgery, irradiation has been attempted for symptomatic relief with varying success ${ }^{12,} 13$. Chemotherapy using vincristine, dacarbazine and cyclophosphamide along with 131I-MIBG therapy has been attempted for patients with systemic metastasis. Radiotherapy may be effective for large tumours, recurrent tumours and patients who are poor candidates for surgery. ${ }^{14}$

CONCLUSION: carotid body tumors are rare, which are mostly benign, sometimes they may not be truly pulsatile. High clinical suspicion and thorough investigation is necessary. Complete resection of the primary mass is the treatment of choice.

\section{REFERENCES:}

1. Shamblin WR, ReMine WH, Sheps SG, Harrison EG. Carotid body tumor - Clinicopathologic analysis of ninety cases. Am J Surg 1971; 122: 732-739.

2. LaMuraglia GM, Fabian RL, Brewster DC, Pile-Spellman J, Darling RC, Cambria RP. The current surgical management of carotid body paragangliomas. J Vasc Surg 1992; 15:10381044. 
3. Lustrin ES, Palestro C, Vaheesan K. Radiographic evaluation and assessment of paragangliomas. Otolaryngol Clin North Am 2001; 34: 881-906.

4. Dimakakos PB, Kotsis TE. Carotid body paraganglioma: review and surgical management. Eur J Plast Surg 2001; 24: 58-65.

5. Razakaboay M, Maillefert JF, Wendling D. Bone metastases from a paraganglioma. A review of five cases. Rev Rhum Engl Ed 1999; 66:86-91.

6. Casati A, Ferri M , Lucandri G, Fornari F, Sciacca V. [Carotid body tumors. Apropos a case and a review of the literature]. G Chir 1999; 20: 229-232.

7. Lack EE, Cubilla AL, Woodruff JM. Paragangliomas of the head and neck region. A pathologic study of tumors from 71 patients. Hum Pathol 1979; 10: 191-218.

8. Sajid MS, Hamilton G, Baker DM. A multicenter review of carotid body tumour management. Eur J Vasc Endovasc Surg 2007; 34: 127-130.

9. Davidovic LB, Djukic VB, Vasic DM, Sindjelic RP, Duvnjak SN. Diagnosis and treatment of carotid body paraganglioma: 21 years of experience at a clinical center of Serbia. World J Surg Oncol 2005; 3: 10.

10. Grufferman S, Gillman MW, Pasternak LR, Peterson CL,Young WG Jr. Familial carotid body tumors: case report and epidemiologic review. Cancer 1980: 46: 2116-2122.

11. Hallett JW, Nora JD, Hollier LH, Cherry KJ, Pairolero PC. Trends in neurovascular complications of surgical management for carotid body and cervical paragangliomas: A fiftyyear experience with 153 tumors. J Vasc Surg 1988; 7:284-291.

12. Muhm M, Polterauer P, Gstöttner W. Diagnostic and therapeutic approaches to carotid body tumors. Review of 24 patients. Arch Surg 1997; 132: 279-284.

13. Lázaro B, Klemz M, Flores MS, Landeiro JA. Malignant paraganglioma with vertebral metastasis: case report. Arq Neuropsiquiatr 2003; 61: 463-467.

14. Sykes JM, Ossoff RH. Paragangliomas of the head and neck Otolaryngol Clin North Am 1986; 19: 755-767.

Fig 1: CT SCAN OF NECK

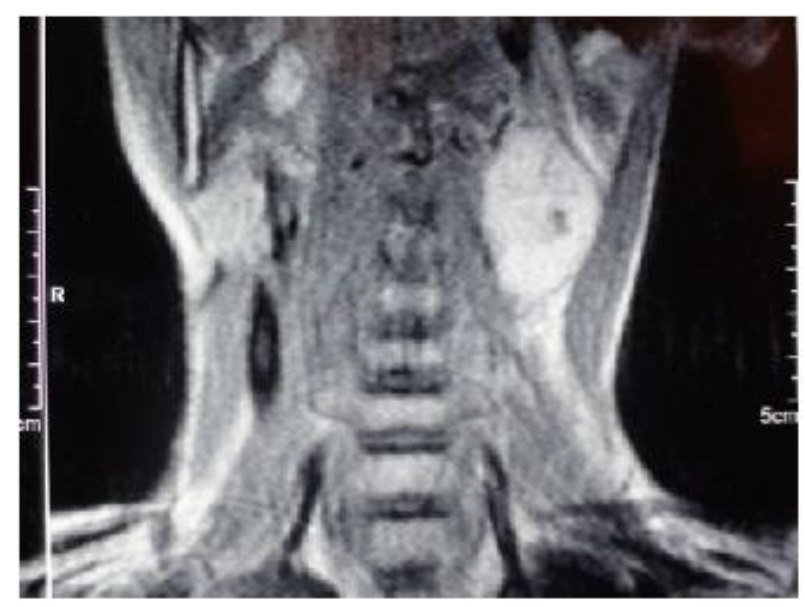




\section{CASE REPORT}

\section{FIG 2: TUMOUR IN BETWEEN ICA AND ECA}

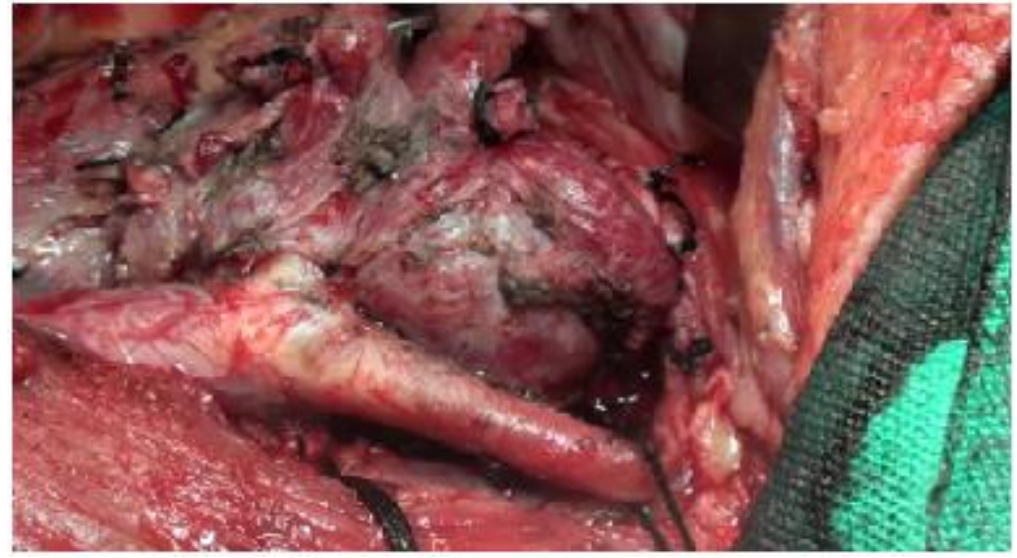

\section{AUTHORS:}

1. Gurukiran C.S.

2. Pavan B.M.

3. Naveen Kumar M.

4. Suhas $\mathrm{S}$.

\section{PARTICULARS OF CONTRIBUTORS:}

1. Associate Professor, Department of General Surgery, Sree Siddartha Medical College \& Research Hospital, Tumkur.

2. Assistant Professor, Department of General Surgery, Sree Siddartha Medical College \& Research Hospital, Tumkur.

3. Assistant Professor, Department of General Surgery, Sree Siddartha Medical College \& Research Hospital, Tumkur.
4. Senior Resident, Department of General Surgery, Sree Siddartha Medical College \& Research Hospital, Tumkur.

\section{NAME ADRRESS EMAIL ID OF THE} CORRESPONDING AUTHOR:

Dr. Gurukiran C.S.

Associate Professor,

Department of Surgery, SSMC,

Agalakote, Tumkur - 7

Email-csgurukiran@gmail.com

Date of Submission: 18/07/2013.

Date of Peer Review: 20/07/2013.

Date of Acceptance: 08/08/2013.

Date of Publishing: 14/08/2013 